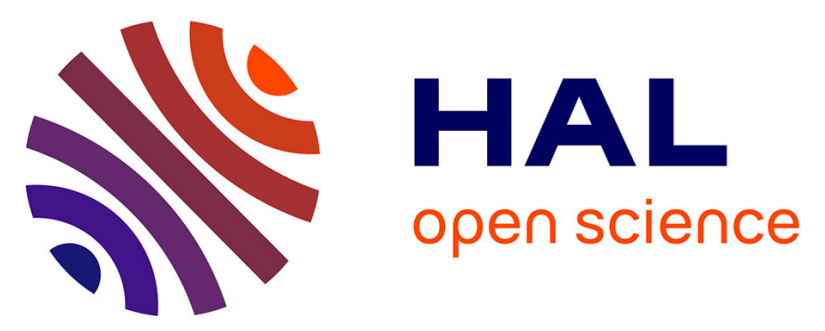

\title{
Response of a diuron-degrading community to diuron exposure assessed by real-time quantitative PCR monitoring of phenylurea hydrolase $\mathrm{A}$ and $\mathrm{B}$ encoding genes
}

S. Pesce, J. Beguet, N. Rouard, M. Devers Lamrani, F. Martin Laurent

\section{To cite this version:}

S. Pesce, J. Beguet, N. Rouard, M. Devers Lamrani, F. Martin Laurent. Response of a diurondegrading community to diuron exposure assessed by real-time quantitative PCR monitoring of phenylurea hydrolase A and B encoding genes. Applied Microbiology and Biotechnology, 2013, 97 (4), p. 1661 - p. 1668. 10.1007/s00253-012-4318-3 . hal-00794785

\section{HAL Id: hal-00794785 \\ https://hal.science/hal-00794785}

Submitted on 26 Feb 2013

HAL is a multi-disciplinary open access archive for the deposit and dissemination of scientific research documents, whether they are published or not. The documents may come from teaching and research institutions in France or abroad, or from public or private research centers.
L'archive ouverte pluridisciplinaire HAL, est destinée au dépôt et à la diffusion de documents scientifiques de niveau recherche, publiés ou non, émanant des établissements d'enseignement et de recherche français ou étrangers, des laboratoires publics ou privés. 


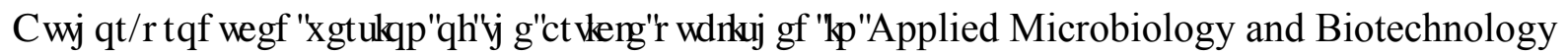
2010 - DOI 10.1007/s00253-012-4318-3

The original publication is available at http://link.springer.com/

\title{
Response of a diuron-degrading community to diuron exposure assessed by real-time quantitative PCR monitoring of phenylurea hydrolase $A$ and $B$ encoding genes
}

Stéphane Pesce $^{1^{*}}$, Jérémie Beguet ${ }^{2}$, Nadine Rouard ${ }^{2}$, Marion Devers-Lamrani ${ }^{2}$, Fabrice MartinLaurent $^{2}$

(1) Irstea, UR MALY, 3 bis quai Chauveau-CP 220, 69336 Lyon, France

(2) INRA, UMR 1347 Agroecologie, 17 rue Sully, B.P. 86510, 21065 Dijon Cedex, France

* Stephane Pesce : stephane.pesce@irstea.fr

Received: 17 April 2012

Revised: 10 July 2012

Accepted: 17 July 2012

Published online: 2 August 2012

\begin{abstract}
A real-time quantitative PCR method was developed to detect and quantify phenlylurea hydrolase genes' (puhA and puhB) sequences from environmental DNA samples to assess diuron-degrading genetic potential in some soil and sediment microbial communities. In the soil communities, mineralization rates (determined with $\left[\right.$ ring- $\left.{ }^{14} \mathrm{C}\right]$-labeled diuron) were linked to diuron-degrading genetic potentials estimated from puhB number copies, which increased following repeated diuron treatments. In the sediment communities, mineralization potential did not depend solely on the quantity of puhB copies, underlining the need to assess gene expression. In the sediment samples, both puhB copy numbers and mineralization capacities were highly conditioned by whether or not diurontreated soil was added. This points to transfers of degradative potential from soils to sediments. No puhA gene was detected in soil and sediment DNA extracts. Moreover, some sediments exhibited high diuron mineralization potential even though puhB genes were not detected, suggesting the existence of alternative diuron degradation pathways.
\end{abstract}

\section{Electronic supplementary material}

The online version of this article (doi:10.1007/s00253-012-4318-3) contains supplementary material, which is available to authorized users.

\section{Keywords}

Biodegradation Microbial communities Mineralization Pesticides Phenylurea hydrolases qPCR 


\section{Introduction}

Agriculture is a major source of diffuse contamination of surface waters by pesticides (Schwarzenbach et al. 2006). The phenylurea herbicide diuron (3-(3,4-dichlorophenyl)-1,1-dimethylurea, Bayer CropScience), listed as a priority pollutant by the European Water Framework Directive $(2000 / 60 / \mathrm{EC})$, is one of the pesticides most frequently detected in freshwater ecosystems. Several recent studies have shown the presence of this herbicide in various rivers draining agricultural watersheds (e.g., Schuler and Rand 2008; Stork et al. 2008; Pesce et al. 2010a). Microbial degradation is considered to be a major driver of the natural attenuation of diuron in the environment (Khurana et al. 2009; Sharma and Suri 2011).

We know that natural soil and aquatic microbial communities can adapt to the degradation of diuron following prolonged exposure in both field and experimental systems (e.g., Dellamatrice and Monteiro 2004; Sørensen et al. 2003; Pesce et al. 2009, 2010b). Specific information on the potential of biodegradation can be obtained by examining functional genes encoding enzymes involved in degradation pathways (Bombach et al. 2010; Smith and Osborn 2009). One prerequisite for such an approach is knowledge of the degradation pathway and its underlying genetics. The only genetic characterizations of hydrolytic diuron-degrading enzymes published to date were performed by Turnbull et al. (2001) and by Khurana et al. (2009), who described two phenlylurea hydrolase (puh) genes from Arthrobacter globiformis (puhA gene) and Mycobacterium brisbanense (puhB genes), respectively. These two genes share $79 \%$ nucleotide identity and $83 \%(382 / 461)$ amino acid identity being related to the metal-dependent hydrolase A subfamily (CD01299) of the amidohydrolase superfamily. Interestingly, both PuhA and PuhB are able to transform several other phenylureas such as chlorotoluron, isoproturon or linuron; despite that they have been isolated from bacteria selected for diuron degradation, both enzymes displayed the greatest catalytic efficiency with linuron $\left(\mathrm{k}_{\text {cat }} / \mathrm{K}_{\mathrm{m}}\right.$ values of 37.5 and $33.9 \mu \mathrm{M}^{-1} \mathrm{~min}^{-1}$, respectively) (Khurana et al. 2009). The quantification of these two catabolic genes by real-time quantitative polymerase chain reaction (qPCR) carried out on nucleic acids extracted from environmental samples could be a new step forward in the assessment of in situ biodegradation potential of diuron and other related phenylureas. This new approach allows the monitoring of the abundance of diuron degraders in regard with the estimation of biodegradation potential in contaminated areas by radiorespirometry.

The main aim of this study was thus to develop a qPCR assay to study diuron biodegradation potential in soil and sediment environments by quantifying puhA and puhB sequences using specifically designed new primer pairs. The mineralization potentials for $\left[\right.$ ring- $\left.{ }^{14} \mathrm{C}\right]$-labeled diuron were also estimated to determine whether mineralization kinetics were linked to diuron-degrading genetic potentials measured by qPCR.

\section{Materials and methods}

\section{Soil and sediment sampling}

Soil and sediment samples were collected from the watershed of the river Morcille located in the French Beaujolais area (longitude, $4^{\circ} 60^{\prime} \mathrm{E}$; latitude, $46^{\circ} 15^{\prime} \mathrm{N}$ ). Vineyards occupy more than $65 \%$ of the total watershed area $\left(8.5 \mathrm{~km}^{2}\right)$, which is chronically contaminated by the herbicide diuron in both terrestrial and aquatic compartments (Montuelle et al. 2010).

A composite soil sample of the upper-layer horizon $(0-20 \mathrm{~cm})$ made up of 15 randomly chosen subsamples was collected in January 2008, compliant with ISO 10381-6 guidelines (ISO 1993) from a vineyard plot adjacent to the Morcille River. The soil sample was subdivided in two subsamples which were incubated in the dark at $20^{\circ} \mathrm{C}$ for 4 weeks before the aquatic microcosms were set up. One subsample was treated three times (initially and then once a week during the first 2 weeks) with diuron at a typical agronomic dose $(1.2 \mathrm{mg} / \mathrm{kg}$ of soil dry weight equivalent corresponding to $1.2 \mathrm{~kg} / \mathrm{ha}$ for top $10 \mathrm{~cm}$ of arable soils), while the other one was not treated with diuron (control soil). It should be noted that when its use was still permitted in France, diuron was generally applied only once a year on vineyard parcels, but we decided to repeat the treatment to induce a significant stimulation of the diuron biodegradation potential. 
The sediment sampling was performed in February 2008, before the pesticide application period, at the unpolluted and forested upstream reference site. The sampled sediments were placed in aquarium microcosms ( $3 \mathrm{~kg} \mathrm{dw}$ per microcosm) filled with river water $(7 \mathrm{~L})$, with or without supplementation with diuron $(10 \mu \mathrm{g} / \mathrm{L})$ or with the above diuron-treated vineyard soil $(300 \mathrm{~g} \mathrm{dw})$ to experimentally assess the impact of runoff and erosion processes on the adaptation of riverine sediment microbial communities to diuron degradation. In each microcosm, sediments (and soil when present) were homogenized once a week by manual mixing. This homogenization was also performed just before sampling, which consisted of collecting $300 \mathrm{~g}$ of sediments (and soil when present). More details on the experimental procedure can be found in Pesce et al. $(\underline{2010 b})$. Sediments were sampled for analysis on day 0 and after 2,4 , and 9 weeks in the microcosms.

\section{Characterization of diuron exposure}

Diuron concentrations in soils and sediments (for the microcosm experiment only) were measured by a qualified laboratory (CERECO S.A., Nîmes, France) using LC/MS/MS following standardized analytical methods and quality assurance protocols. The quantification limit was $1 \mu \mathrm{g} / \mathrm{kg}$ of soil or sediment $(\mathrm{dw})$. Diuron concentrations in the water phase (Morcille River and microcosms) were determined using liquid chromatography and mass spectrometry as described in Pesce et al. (2010c). The quantification limit was $0.005 \mu \mathrm{g} / \mathrm{L}$.

\section{$\underline{\text { DNA extraction and quantification }}$}

Soil and sediment DNA was extracted using the FAST DNA kit (QBIOgene, Illkirch, France) according to the manufacturer's instructions. Genomic DNA concentrations were determined by fluorometry using the Qubit assay (Invitrogen).

\section{$\underline{\text { Inhibition test }}$}

Before qPCR assays, the absence of PCR inhibitors in the environmental DNA extracts was verified by adding a known amount of the pGEM-T Easy plasmid vector (Promega, France) to the extracted DNAs. The control plasmid was then quantified in all samples by qPCR using a StepOnePlus qPCR machine (Applied Biosystems, USA) and SP6 and T7 universal primers with the method reported by Henry et al. (2006). The absence of detectable inhibition in the assay was confirmed in all the sediment DNAs, while soil DNAs were diluted 1:10 with MilliQ water to avoid inhibition.

\section{Primer design}

Two sets of primers were designed to specifically target the puhA (GenBank accession number EU851877) and puhB (GenBank accession number EU851876) genes isolated from A. globiformis strain D47 and M. brisbanense strain JK1, respectively (Turnbull et al. 2001; Khurana et al. 2009). Primer sets were designed to follow recommendations for SYBR-Green qPCR assay: length of the amplicon (from 100 to $200 \mathrm{bp}$ ), $50 \%$ GC content, length averaging 20 nucleotides, and annealing temperature averaging $60^{\circ} \mathrm{C}$. To meet these requirements, the Primer3 program (v. 0.4.0) was used with the following constraints: product size ranges 100-200 bp; primer size Min 18, Opt 20, Max 22; Primer Tm Min $57^{\circ} \mathrm{C}$, Opt $60{ }^{\circ} \mathrm{C}$, Max $62{ }^{\circ} \mathrm{C}$; primer GC $\%$ Min $40 \%$, Opt $50 \%$, and Max $60 \%$ (Rozen and Skaletsky 2000). Among the primer pairs proposed by Primer3, two were selected: puhA $\mathrm{A}_{\mathrm{f}}$ 5'-ACC GTG TTC GAC ACG TAC AA-3', puhA $_{\mathrm{r}}$ 5'-GCC CGA TGA AGT GGA AAT C-3', puhB

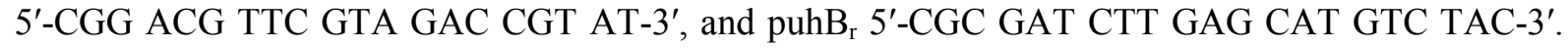
The specificity of each of the primers was checked in silico using BlastN. Annealing with a temperature gradient from 55 to $63{ }^{\circ} \mathrm{C}$ was carried out with DNA extracted from diuron-degrading bacterial consortia harboring both puhA and puhB genes (unpublished). Results confirmed that for both genes, the optimal annealing temperature was $60^{\circ} \mathrm{C}$. 


\section{Quantification of 16S rRNA gene, puhA and puhB sequences in soil and sediment samples}

The abundance of the total bacterial community was estimated by qPCR assay targeted on 16S rRNA gene sequences using the universal bacterial primers $341 \mathrm{f}$ (5'-CCT ACG GGA GGC AGC AG-3') and 534r (5'-ATT ACC GCG GCT GCT GGC A-3') according to Lopez-Gutierrez et al. (2004). The abundance of the diuron-degrading community was estimated by qPCR targeted on either puhA or puhB, using specific primer pairs reported above. The relative abundance of the diuron-degrading community within the total bacterial community was estimated by calculating the $($ puhA + puhB) $/ 16 \mathrm{~S}$ rRNA gene ratio.

Briefly, quantitative PCR assays were carried out with the StepOnePlus ${ }^{\mathrm{TM}}$ System (Applied Biosystems) using SybrGreen ${ }^{\circledR}$ as the detection system in $15 \mu 1$ of reaction volume containing SYBR Green PCR Master Mix (Absolute QPCR SYBR Green Rox ABgene, France), 100 ng of T4 gp 32 (Qbiogene, France), $2 \mu \mathrm{M}$ of each primer, and $2 \mu \mathrm{l}$ of community DNA (i.e., $10-20 \mathrm{ng}$ DNA). The qPCR conditions were $15 \mathrm{~min}$ at $95^{\circ} \mathrm{C}$ for enzyme activation, 10 "touchdown" denaturing cycles $(15 \mathrm{~s}$ at $95{ }^{\circ} \mathrm{C}$ ), primer annealing $\left(45 \mathrm{~s}\right.$ from 64 to $60^{\circ} \mathrm{C} ;-0.5^{\circ} \mathrm{C}$ per cycle) and extension $\left(45 \mathrm{~s}\right.$ at $\left.72{ }^{\circ} \mathrm{C}\right)$, and 30 cycles of $15 \mathrm{~s}$ at $95^{\circ} \mathrm{C}, 45 \mathrm{~s}$ at $60^{\circ} \mathrm{C}$, and $45 \mathrm{~s}$ at $72^{\circ} \mathrm{C}$. The final step consisted of $7 \mathrm{~min}$ at $72{ }^{\circ} \mathrm{C}$. Melting curves were obtained after qPCR amplification by increasing the temperature from 80 to $95{ }^{\circ} \mathrm{C}$ (temperature ramp $0.3{ }^{\circ} \mathrm{C} \mathrm{s}^{-1}$ ). Calibration curves were plotted from previously cloned puhA and puhB PCR products obtained from the diuron-degrading consortium. Recombinant plasmids were linearized using the SalI restriction enzyme and diluted tenfold from $10^{8}$ to $10^{1}$ copies. Standard curves relating the $\log$ of the copy number of the target gene to a function of the $\mathrm{Ct}$ (cycle threshold) were generated: $\log ($ puhA $)=-3.39 \times \mathrm{Ct}+34.48 \quad\left(\mathrm{r} \quad{ }^{2}=0.99, \quad\right.$ qPCR $\quad$ efficiency $\left.=97.37 \%\right)$; $\log ($ puhB $)=-3.34 \times \mathrm{Ct}+33.99\left(\mathrm{r}^{2}=0.99, \mathrm{qPCR}\right.$ efficiency $\left.=99.13 \%\right)$. Three replicates were run for each gene target. Three non-template controls were also run for each gene target.

\section{puhB sequence diversity amplified by qPCR from environmental DNA extracts}

To check for the specificity of puhB qPCR assay obtained from environmental DNA matrices, we cloned qPCR amplicons into the pGem-T Easy vector system according to the manufacturer's instructions (Promega, France). Recombinant clones were screened by PCR using SP6 and T7 universal primers. Forty clones from environmental samples $(20$ from replicate "treated soils", week 0 numbered from 1 to 20; 20 from replicate "sediment + treated soil", week 4 numbered from 21 to 40) were randomly selected for sequencing by Beckman Genomics (Takeley, UK). The nucleotidic sequences of puhB were aligned using the ClustalX program (Thompson et al. 1997).

\section{Estimation of diuron mineralization potential}

The ability of soil and aquatic microbial communities to mineralize diuron was determined by radiorespirometry as described in Soulas (1993). Briefly, soil and sediment samples were treated with uniformly ${ }^{14} \mathrm{C}$-ring-labeled diuron [specific activity $567 \mathrm{MBq} / \mathrm{mmol}$, radiochemical purity $99 \%$ (Sigma Aldrich)]. Soil samples (10 g dw) were moistened to $20 \%$ of their water-holding capacity and spiked with diuron to reach a final concentration of $1.2 \mathrm{mg} / \mathrm{kg}$ of soil (in the range of the agronomic dose). Sediment samples ( $10 \mathrm{~g} \mathrm{dw})$ were immersed in $50 \mathrm{~mL}$ of $0.2 \mu \mathrm{M}$ filtered river water and spiked with diuron to reach a final concentration of $10 \mu \mathrm{g} / \mathrm{L}$ river water. Triplicates of soil and sediment samples were incubated in the dark at $20{ }^{\circ} \mathrm{C}$ for 12 weeks. ${ }^{14} \mathrm{CO}_{2}$ resulting from the mineralization of ${ }^{14} \mathrm{C}$-diuron was trapped in $5 \mathrm{~mL}$ of $0.2 \mathrm{M} \mathrm{NaOH}$ solution and analyzed by liquid scintillation counting using ACS II (Amersham) scintillation fluid. Lag times before mineralization takes place were estimated by determining diuron dissipation time $5 \%$ (DT5) during mineralization kinetics using a log-normal regression model. 


\section{Results}

Diuron mineralization and phenylurea hydrolases A and B encoding genes' quantification in vineyard soil samples

Figure 1 gives mean cumulative diuron mineralization kinetics obtained for composite vineyard soil samples, incubated for 4 weeks and subjected (treated) or not (control) to three successive treatments with diuron in the laboratory. At the end of the mineralization experiments (12 weeks), treated soil showed a 2.5 -fold higher ability to mineralize diuron (mean $\pm \mathrm{SD}=53.3 \pm 0.9 \%$; no initial lag phase) than control soil (20.7 $\pm 2.7 \%$; initial lag phase of about 2 weeks), confirming that microbial communities exposed to diuron in the laboratory had indeed increased their potential to rapidly mineralize diuron (Fig. 1).

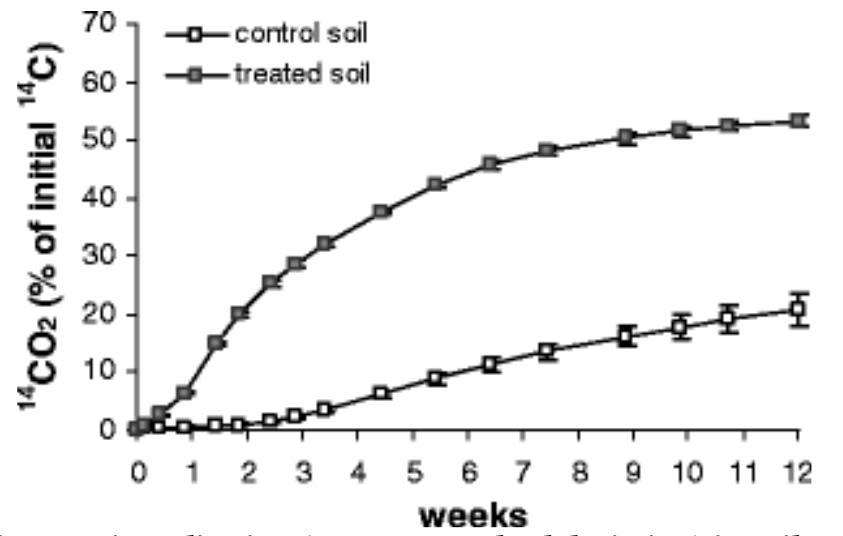

Fig. 1 Time course of diuron mineralization (mean \pm standard deviation) in soils previously treated or not (control) with diuron

Three independent qPCR assays were performed to quantifiy the puhA, puhB, and 16S rRNA gene sequences from DNAs extracted at the end of the 4-week incubation period from control and diuron soils. Treated and control soils exhibited no significant difference in the number of 16S rRNA gene copies, which was close to $5.5 \times 10^{5}\left(\mathrm{SD}=0.8 \times 10^{5}\right)$ copies $^{-1}$ soil DW (data not shown). The puhA sequences were not amplified in either of the soils, whereas puhB sequences were about 6.5 times higher in the treated soil ( $39.8 \pm 11.5$ copies per $10^{5} 16 \mathrm{~S}$ rRNA gene copies) than in the control $\left(6.1 \pm 2.2\right.$ copies per $10^{5} 16 \mathrm{~S}$ rRNA gene copies; Fig. 2 ).

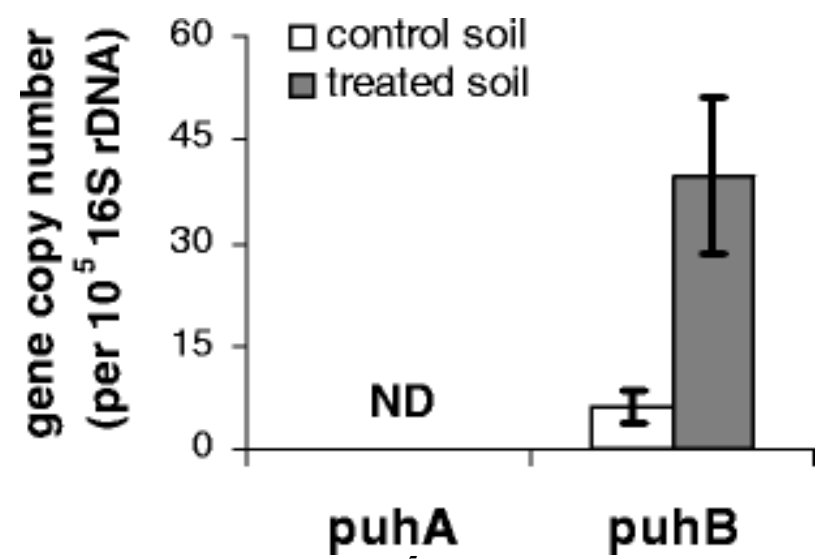

Fig. 2 Number of puhA and puhB sequences per $10^{5} 16 \mathrm{~S}$ rRNA gene sequences (mean \pm sd) estimated by qPCR assays carried out on DNA extracted from diuron-treated or control soils. ND not detected 
Diuron mineralization and phenylurea hydrolases A and B encoding genes' quantification in sediment samples

Sediments freshly collected in the upstream section of the Morcille River exhibited a low diuron mineralization potential [about $5 \%{ }^{14} \mathrm{CO}_{2}$ resulting from the mineralization of ${ }^{14} \mathrm{C}$-diuron after 12 weeks (data not shown)], and neither puhA nor puhB genes were detected in initial sediment microbial communities (detection limit estimated to $10^{2}$ copies of puhA or B per nanogram of environmental DNA).

Two weeks after the microcosms were set up, no significant differences could be observed on the maximum cumulative percentage of diuron mineralization (Fig. 3a), maximal mineralization rate (Fig. 3b) and diuron DT5 (Fig. 3c) estimated in the sediments subjected to the three treatments (i.e., control sediments, sediments + diuron, and sediments + diuron-treated soil). After 4 and 9 weeks, an increase in maximum cumulative percentage of diuron mineralization (Fig. $\underline{3 a}$ ) was recorded in the microcosms supplemented with diuron or diuron-treated soil compared with control. Sediments supplemented with diuron-contaminated soil showed lower DT5 values at weeks 4 and 9 (Fig. $\underline{3 c}$ ), revealing a shorter initial lag phase in mineralization kinetics, as well as a higher maximal cumulative percentage of mineralization (Fig. $\underline{3 a}$ ) and a higher maximal mineralization rate at the last sampling time (Fig. $\underline{3 b})$.

The puhA gene was never detected in the sediment samples. By contrast, puhB sequences were only detected in sediment supplemented with treated soil (Fig. 3d). In sediment supplemented with treated soils, the number of puhB copies exceeded 6 per $10^{5} 16 \mathrm{~S}$ rRNA gene copies at week 2 , before stabilizing at about 3 per $10^{5} 16 \mathrm{~S}$ rRNA gene gene copies (weeks 4 and 9).

a

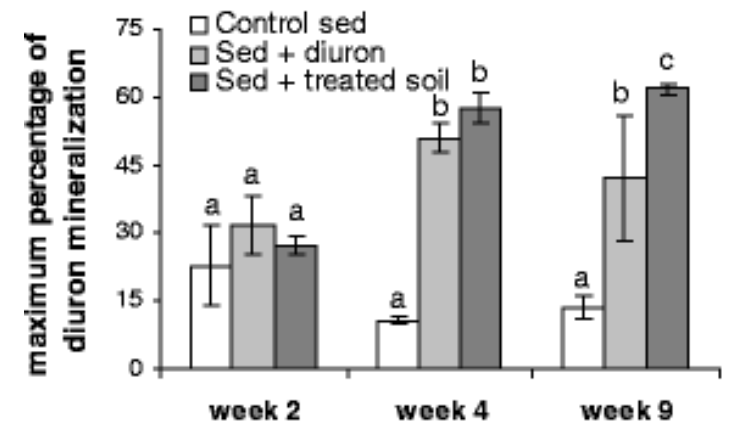

c

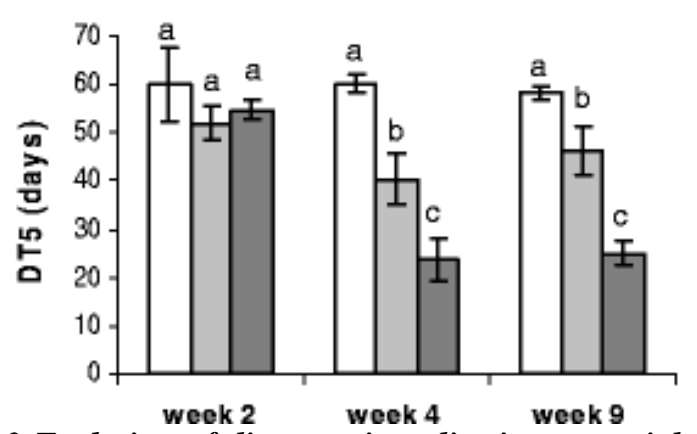

b

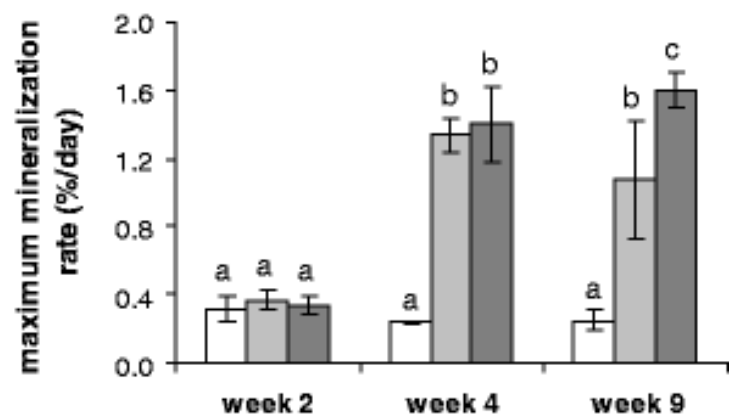

d

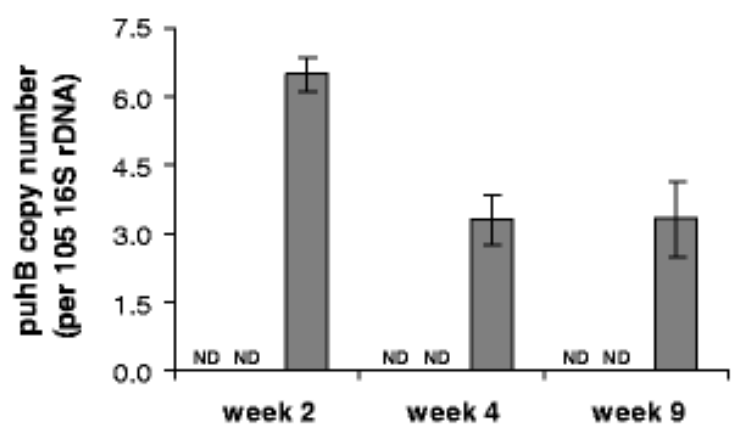

Fig. 3 Evolution of diuron mineralization potential of sediments throughout the microcosm study expressed as time course of maximum cumulative percentage of diuron mineralization (a, percentage of ${ }^{14} \mathrm{CO}_{2}$ evolved from ${ }^{14} \mathrm{C}$-diuron), maximum mineralization rate (b, percentage of ${ }^{14} \mathrm{CO}_{2}$ evolved from ${ }^{14} \mathrm{C}$-diuron per day), diuron dissipation time $25 \%$ (c, DT5, time required for $5 \%$ of ${ }^{14} \mathrm{CO}_{2}$ to be evolved from ${ }^{14} \mathrm{C}$-diuron). Diurondegrading genetic potential was also addressed by quantifying the relative abundance of puhB sequences $(d$, number of puhB sequences per $10^{5} 16 \mathrm{~S}$ rRNA gene sequences). Measurements were made on sediment samples collected respectively after 2, 4, and 9 weeks in microcosms supplemented or not (Control sed) with diuron $($ Sed + diuron) or with treated soil $($ Sed + treated soil) and data represent mean values $( \pm S D)$. At each sampling time, different lowercase letters indicate significant differences (ANOVA, $p<0.05)$ between treatments. ND not detected 


\section{Analyses of sequences obtained with puhB primer set}

To verify the specificity of the puhB primer set, qPCR amplicons obtained from soil and sediment DNA extracts were cloned and sequenced. Multiple alignment of nucleotide sequences was performed (Fig. S1). Out of the 40 clones sequenced, 32 sequences showed $100 \%$ similarity to the reference puhB sequence of $\mathrm{M}$. brisbanense strain JK1, and 7 sequences showed similarities ranging from 93 to $99 \%$ to puhB sequence (sequence $23,99 \%$ homology with puhB and $98 \%(44 / 45)$ similarity with PUH B; sequence 30, $98 \%$ homology and $96 \%$ (43/45) similarity; sequences $25,29,38,39$, and 40, $93 \%$ homology and $96 \%$ (43/45) similarity). It is noteworthy that diverging PuhB sequences were all characterized in sediment samples (initially supplemented with treated soils). Interestingly, these sequences were found to have non-synonymous mutations responsible for PUH B amino acid sequence changes (Fig. $\underline{4})$.

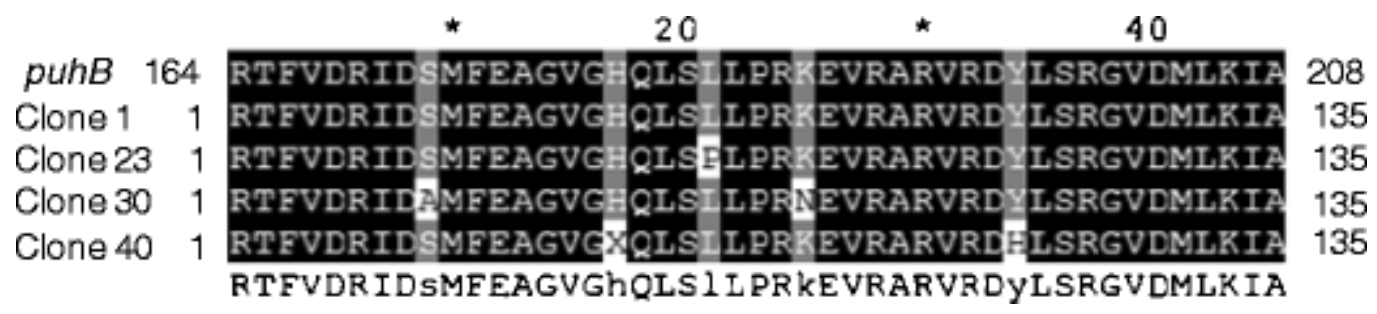

Fig. 4 Multiple alignments of PUH B sequence of M. brisbanense strain JK1 with amino acid deduced from nucleotidic puhB sequences amplified from DNA extracted from soil and sediments. Over the 39 sequences identified, 32 identical to clone 1 are $100 \%$ identical to PUH B. Clones 23 and 30 are showing 98 (44/45) and $96 \%$ (43/45) of identity with PUHB. Five sequences were identical to clone 40 showing $96 \%$ (43/45) of identity with PUHB

\section{Discussion}

The primer sets designed here revealed good specificities for the targeted genes with both isolated bacterial consortia (puhA and puhB, unpublished) and soil and sediment communities (puhB) DNA as template. No puhA gene was detected in soil and sediment DNA extracts, even in samples exhibiting a high potential for diuron mineralization. This is quite surprising because bacteria harboring this gene were recently isolated from soil samples collected in the same vineyard plot (unpublished). One might suspect a methodological bias, but this is unlikely because puhA sequences were correctly amplified in isolated consortia using the same protocol (unpublished), and we checked the absence of PCR inhibitors in all the environmental DNAs. The estimated detection limit being $10^{2}$ copies per nanogram of soil DNA, we cannot rule out the presence of puhA sequences below this detection limit.

By contrast, puhB sequences were detected by qPCR in the DNA extracts purified from vineyard soil. Interestingly, most of the puhB sequences obtained from the studied vineyard soil were $100 \%$ identical with the published puhB sequence, which was described from a M. brisbanense strain isolated from an Australian soil located in Queensland (Khurana et al. 2009). Similar findings were reported for other pesticides, such as the herbicide atrazine, revealing that pesticide-degrading genes are widespread and sometimes highly conserved over the world (Sadowsky $\underline{2010}$ ). Our results reveal the presence of a diuron degradation potential even in control soil samples, which were not treated with diuron in the laboratory. However, this is consistent with the history of treatment, namely repeated application of diuron for many years in the vineyard plot from which the soil samples originated. Rapid, extensive mineralization of diuron or related phenylurea herbicides (i.e., within a few days) has often been observed in soil repeatedly treated with these compounds, illustrating the capability of natural microbial communities to adapt to substituted phenylurea metabolism (e.g., Dellamatrice and Monteiro 2004; Sørensen et al. 2003; El-Sebai et al. 2005). This was confirmed here since the vineyard soil microbial community was able to mineralize about $20 \%$ of ${ }^{14} \mathrm{C}$-diuron within 
12 weeks with a maximal mineralization rate of about $0.4 \%$ per day. This mineralization potential was appreciably lower than that observed with a composite soil sample collected previously in the same plot, which exhibited a maximum percentage of diuron mineralization and a maximum mineralization rate of about $36 \%$ (32\% after 12 weeks) and $0.6 \%$ per day, respectively (Pesce et al. 2009). This difference in mineralization potential can be explained by different sampling period, soils having been sampled before diuron application (February 2008, present study) and after diuron application (June 2007, Pesce et al. 2009). The temporal variability of the potential of mineralization of isoproturon, another substituted urea, in an agricultural soil according to agricultural practices was also underlined by Hussain (2010). Interestingly, puhB sequences obtained from the studied vineyard soil were $100 \%$ identical with the published puhB sequence, which was described from a M. brisbanense strain isolated from an Australian soil located in Queensland (Khurana et al. 2009). Similar findings were reported for other pesticides, such as the herbicide atrazine, revealing that pesticide-degrading genes are widespread and sometimes highly conserved over the world (Sadowsky 2010).

Neither puhA nor puhB was detected in the sediment samples that were not supplemented with soil extracts ("control sediments" and "sediments + diuron"). By contrast, puhB genes were successfully quantified in the sediments supplemented with the treated soils. Interestingly, among puhB sequences retrieved from sediments, several of them were found to be slightly divergent from the reference sequence. Nonetheless, at the amino acid level, these diverging sequences were from 96 to $98 \%$ (i.e., two or one nonsilencing mutation, respectively) identical to PUHB thereby indicating that this gene sequence is highly conserved. According to the homology model and proposed catalytic mechanism of PUHB, the observed mutations did not occur in the catalytic site Khurana et al. (2009).

The abundance of puhB genes in the sediments was close to six copies per $10^{5} 16 \mathrm{~S}$ rRNA gene copies after 2 weeks in the micrososms. In the treated soil, this value was about eight times higher showing that the relative proportions of puhB copy numbers in sediment and soil, respectively, were comparable to the distribution between sediment $(3 \mathrm{~kg} \mathrm{dw})$ and soil $(0.3 \mathrm{~kg} \mathrm{dw})$ quantities in the microcosms. All these results thus suggest that puhB genes detected in the sediments may mainly originate from the treated soil. Keeping in mind that in a previous study diuron degraders originating from the treated vineyard were found unable to persist in sediments (Pesce et al. 2010b), we can hypothesize that they contribute to sediment microbial adaptation to diuron mineralization via different processes not elucidated yet, but which may include survival of soil diuron degraders in the sediment, or gene exchange mechanisms between soil (donor) and sediment (receiver) bacterial species (including puhB, according to our results). However, this hypothesis cannot be the sole explanation because some of puhB sequences obtained from sediment samples slightly diverging from those of sequences isolated from soil were identical to M. brisbanense strain JK1 (Khurana et al. 2009). One could hypothesize that the microbial communities of the sediment have their own genetic potential for adaptation to diuron mineralization, which was indeed shown to be increased in the sediments exposed for at least 4 weeks to the herbicide (in comparison with control sediments). Or alternatively or in combination, one may also argue that the growth of soil populations harboring the divergent puhB sequences was favored in the sediment conditions while they remain under the detection limit in the native soil. It is noteworthy that the sediments supplemented with diuroncontaminated soil exhibited the highest mineralization percentages and mineralization rates (after 9 weeks) and the shortest initial lag phase in their mineralization kinetics (after 4 and 9 weeks). We can hypothesize that this results from the expression of different puhB genetic potentials or is due to the addition of organic matter originating from soil to the sediment, which will favor microbial growth and activity.

The accurate quantification by qPCR of functional genes encoding key reactions in degradation pathways of pesticides offers the opportunity to investigate the potential for their biodegradation within various compartments of the environment (Vieublé-Gonod et al. 2006; Smith and Osborn 2009). Several studies have thus attempted to link the abundance of the atrazine-degrading community with atrazine mineralization activity using this type of approach (e.g., Martin-Laurent et al. 2004; Monard et al. 2008). The present study is the first aimed at (1) assessing the diuron-degrading genetic potential in soil and sediment microbial communities and (2) linking it with diuron mineralization 
activity. The results obtained with soils samples reveal that repeated treatments with diuron led to a significant increase in the number of puhB sequences, which were about 6.5 times more abundant in the treated soil than in the control. This is in line with previous studies also reporting an increase in the abundance of the tfdA gene coding the first enzyme of the 2,4-D biodegradation pathway following prolonged exposure to this herbicide (Bælum et al. 2006; Vieublé-Gonod et al. 2006). Similar observations were also made for several pollutants such as aromatic hydrocarbons (Piskonen et al. 2008) and chlorobenzene (Dominguez et al. 2008) and toluene (Kazy et al. 2010). The increase in the number of puhB sequences in the soil communities was corroborated with a significant increase in the diuron mineralization potential activity, which was about 2.5 times higher for the treated soil than for the control (based on the maximum mineralization percentage after 12 weeks). It reveals a positive relationship between the diuron-degrading genetic and activity potentials for diuron biodegradation processes. The increase in puhB gene copy numbers was also corroborated with a decrease in lag time before mineralization started in the radiorespirometric assays. A similar observation was recently pointed out by Bers et al. (2012), who observed a negative correlation between the number of copies of the linuron hydrolase libA gene and the lag time of linuron mineralization of various soil samples. However, it has to be underlined that quantification of the abundance of functional genes reveals only a genetic potential that might be expressed under favorable conditions (Monard et al. 2010). In the case of diuron, El Sebaï et al. (2010) have shown that the expression of diuron mineralization potential of the soil microflora depends on different environmental factors, such as soil moisture content or climatic conditions. Likewise, Martin-Laurent et al. (2004) revealed that different soils showing similar atrazine-degrading genetic potential may exhibit different atrazine-degrading activities. In the present study, the evolution of the mineralization potential of sediments supplemented with treated soil was not fully in accordance with the number of puhB genes: 2 weeks after the addition of treated soils to the sediments, relatively low diuron mineralization potential was recorded in the microcosms (mineralization kinetics similar to those observed with control sediments), while concomitantly the highest abundance of puhB genes was measured. Assuming that puhB sequences quantified in the sediments mainly originated from the added soil, it could be argued that terrestrial diuron degraders were not yet fully acclimatized to the conditions encountered in the sediment. This confirms that the study of biodegradation gene expression could offer a more powerful indication of effective microbial degrading activity (Devers et al. 2004; Monard et al. 2010). At weeks 4 and 9, both the abundance of puhB genes and the potential of mineralization remained stable, confirming that sediment microbial communities were genetically well adapted to diuron mineralization.

Although we observed a significant increase in the diuron mineralization potential within sediments chronically exposed to diuron $(10 \mu \mathrm{g} / \mathrm{L})$ in microcosms, neither puhA nor puhB was detected in the microbial communities. We have designed primer pairs targeting the only two known genes encoding phenylurea hydrolases A and B responsible for diuron hydrolysis (Khurana et al. 2009; Turnbull et al. 2001). Sequencing analyses of puhB amplicons showed that sequences diverging from the reference were retrieved giving on one hand information that although the primer pair was not degenerated it allows to retrieve genetic diversity. However, on the other hand, it might also be possible that more divergent of puh sequences may not have been amplified under our conditions. Alternatively, keeping in mind that pesticide-degrading enzymes are generally highly conserved (Sadowsky 2010), one could also suggest the existence of other degradation pathways. This means that it is probably necessary to extend the investigation on the degradation pathway of diuron (or more generally of phenylureas) and the underlying genetics to develop molecular tools for monitoring biodegradation processes, especially in order to assess their role in the natural attenuation of pesticides in contaminated environments.

To conclude, this work is to our knowledge the first qPCR-based approach which aims at studying diuron biodegradation potential in soil and sediment environments by quantifying puhB sequences. In soil communities, mineralization kinetics were linked to diuron-degrading genetic potentials, which were enhanced following repeated diuron treatments. In sediment communities, results showed that mineralization potential not only depended on the quantity of puhB copies, confirming the need to assess gene expression. Also, some sediments exhibited high diuron mineralization potential even though puhA and puhB genes were not detected, suggesting the existence of alternative diuron degradation pathways. 


\section{Acknowledgments}

We thank ATT for editing the English-language version of the manuscript and David Bru for technical help in qPCR analysis. This project was supported by funding from the French National Office for the Aquatic Environment (ONEMA; convention no. C000114010), and the authors personally thank Nicolas Domange for insightful discussion.

\section{References}

Bælum J, Henriksen T, Hansen HCB, Jacobsen CS (2006) Degradation of 4-chloro-2methylphenoxyacetic acid in top- and subsoil is quantitatively linked to the class III tfdA gene. Appl Environ Microbiol 72:1476-1486

Bers K, Sniegowski K, De Mot R, Springael D (2012) Dynamics of the linuron hydrolase libA gene pool size in response to linuron application and environmental perturbations in agricultural soil and on-farm biopurification systems. Appl Environ Microbiol 78:27832789

Bombach P, Richnow HH, Kästner M, Fischer A (2010) Current approaches for the assessment of in situ biodegradation. Appl Microbiol Biotechnol 86:839-852

Dellamatrice PM, Monteiro RTR (2004) Isolation of diuron-degrading bacteria from treated soil. Braz Arch Biol Technol 47:999-1003

Devers M, Soulas G, Martin-Laurent F (2004) Real-time reverse transcription PCR analysis of expression of atrazine catabolism genes in two bacterial strains isolated from soil. $\mathrm{J}$ Microbiol Methods 56:3-15

Dominguez RF, da Silva MLB, McGuire TM, Adamson D, Newell CJ, Alvarez PJJ (2008) Aerobic bioremediation of chlorobenzene source-zone soil in flow-through columns: performance assessment using quantitative PCR. Biodegradation 19:545-553

El-Sebai T, Lagacherie B, Cooper JF, Soulas G, Martin-Laurent F (2005) Enhanced isoproturon mineralisation in a clay silt loam agricultural soil. Enhanced isoproturon mineralisation in a clay silt loam agricultural soil. Agron Sustain Dev 25:271-277

El Sebaï T, Devers M, Lagacherie B, Rouard N, Soulas G, Martin-Laurent F (2010) Diuron mineralisation in a Mediterranean vineyard soil: impact of moisture content and temperature. Pest Manag Sci 66:988-995

Henry S, Bru D, Stres B, Hallet S, Philippot L (2006) Quantitative detection of the nosZ gene, encoding nitrous oxide reductase, and comparison of the abundances of $16 \mathrm{~S}$ rRNA, narG, nirK, and nosZ genes in soils. Appl Environ Microbiol 72:5181-5189

Hussain S (2010) Characterization of the isoproturon degrading community: from the field to the gene. Université de Bourgogne, France, p 174

ISO (1993) Soil quality-Sampling-Part 6: guidance on the collection, handling and storage of soil for the assessment of aerobic microbial processes in the laboratory. ISO, Geneva

Kazy SK, Monier AL, Alvarez PJJ (2010) Assessing the correlation between anaerobic toluene degradation activity and bssA concentrations in hydrocarbon-contaminated aquifer material. Biodegradation 21:793-800

Khurana JL, Jackson CJ, Scott C, Pandey G, Horne I, Russell RJ, Herlt A, Easton CJ, Oakeshott JG (2009) Characterization of the phenylurea hydrolase A and B: founding members of a novel aminohydrolase subgroup. Biochem J 418:431-441

Lopez-Gutierrez JC, Henry S, Hallet S, Martin-Laurent F, Catroux G, Philippot L (2004) Quantification of a novel group of nitrate-reducing bacteria in the environment by real-time PCR. J Microbiol Ecol 57:399-407 
Martin-Laurent F, Cornet L, Ranjard L, López-Gutiérrez JC, Philippot L, Schwartz C, Chaussod R, Catroux G, Soulas G (2004) Estimation of atrazine-degrading genetic potential and activity in three French agricultural soils. FEMS Microbiol Ecol 48:425-435

Monard C, Martin-Laurent F, Vecchiato C, Francez AJ, Vandenkoornhuyse P, Binet F (2008) Combined effect of bioaugmentation and bioturbation on atrazine degradation in soil. Soil Biol Biochem 40:2253-2259

Monard C, Martin-Laurent F, Vecchiato C, Devers-Lamrani M, Lima O, Vandenkoornhuyse $\mathrm{P}$, Binet $\mathrm{F}$ (2010) atz gene expressions during atrazine degradation in the soil drilosphere. Mol Ecol 19:749-759

Montuelle B, Dorigo U, Bérard A, Volat B, Bouchez A, Tlili A, Gouy V, Pesce S (2010) The periphyton as a multimetric bioindicator for assessing the impact of land use on rivers: an overview of the Ardières-Morcille experimental watershed (France). Hydrobiologia 657:123-141

Pesce S, Martin-Laurent F, Rouard N, Montuelle B (2009) Potential for microbial diuron mineralisation in a small wine-growing watershed: from treated plots to lotic receiver hydrosystem. Pest Manag Sci 65:651-657

Pesce S, Margoum C, Montuelle B (2010a) In situ relationships between spatio-temporal variations in diuron concentrations and phototrophic biofilm tolerance in a contaminated river. Water Res 44:1941-1949

Pesce S, Martin-Laurent F, Rouard N, Robin A, Montuelle B (2010b) Evidence for adaptation of riverine sediment microbial communities to diuron mineralisation: incidence of run-off and soil erosion. J Soil Sediments 10:698-707

Pesce S, Lissalde S, Lavieille D, Margoum C, Mazzella N, Roubeix V, Montuelle B (2010c) Evaluation of single and joint toxic effects of diuron and its main metabolites on natural phototrophic biofilms using a pollution-induced community tolerance (PICT) approach. Aquatic Toxicol 99:492-499

Piskonen R, Nyyssönen M, Itävaara M (2008) Evaluating the biodegradation of aromatic hydrocarbons by monitoring of several functional genes. Biodegradation 19:883-895

Rozen S, Skaletsky HJ (2000) Primer3 on the WWW for general users and for biologist programmers. In: Krawetz S, Misener S (eds) Bioinformatics methods and protocols: methods in molecular biology. Humana Press, Totowa, NJ, pp. 365-386 (Source code available at http://fokker.wi.mit.edu/primer3/)

Sadowsky MJ (2010) Diversity and evolution of micro-organisms and pathways for the degradation of environmental contaminants: a case study with the s-triazine herbicides. In: Batty LC, Hallberg KB (eds) Ecology of industrial pollution. Cambridge University Press, Cambridge, pp 205-225

Schuler LJ, Rand GM (2008) Aquatic risk assessment of herbicides in freshwater ecosystems of South Florida. Arch Environ Contam Toxicol 54:571-583

Schwarzenbach RP, Escher BI, Fenner K, Hofstetter TB, Johnson CA, von Gunten U, Wehrli B (2006) The challenge of micropollutants in aquatic systems. Science 313:1072-1077

Sharma P, Suri CR (2011) Biotransformation and biomonitoring of phenylurea herbicide diuron. Bioresour Technol 102:3119-3125

Smith CJ, Osborn AM (2009) Advantages and limitations of quantitative PCR (Q-PCR)-based approaches in microbial ecology. FEMS Microbiol Ecol 67:6-20

Sørensen SR, Bending GD, Jacobsen CS, Walker A, Aamand J (2003) Microbial degradation of isoproturon and related phenylurea herbicides in and below agricultural fields. FEMS Microbiol Ecol 45:1-11

Soulas G (1993) Evidence for the existence of different physiological groups in the microbial community responsible for 2, 4-D mineralization in soil. Soil Biol Biochem 25:443-449 
Stork PR, Bennett FR, Bell M (2008) The environmental fate of diuron under a conventional production regime in a sugarcane farm during the plant cane phase. Pest Manag Sci 64:954 963

Thompson JD, Gibson TJ, Plewniak F, Jeanmougin F, Higgins DG (1997) The ClustalX windows interface: flexible strategies for multiple sequence alignment aided by quality analysis tools. Nucleic Acids Res 24:4876-4882

Turnbull GA, Ousley M, Walker A, Shaw E, Morgan JAW (2001) Degradation of substituted phenylurea herbicides by Arthrobacter globiformis strain D47 and characterization of a plasmid-associated hydrolase gene, puhA. Appl Environ Microbiol 67:2270-2275

Vieublé-Gonod L, Martin-Laurent F, Chenu C (2006) 2,4-D impact on bacterial communities, and the activity and genetic potential of 2,4-D degrading communities in soil. FEMS Microbiol Ecol 58:529-537 